\title{
EVALUASI PEMASANGAN APAR DALAM SISTEM TANGGAP DARURAT KEBAKARAN DI GEDUNG BEDAH RSUD DR. SOETOMO SURABAYA
}

\author{
Rizki Fitriana Hambyah \\ Persatuan Alumni Kesehatan Masyarakat Indonesia \\ (PERSAKMI) Provinsi Jawa Timur \\ E-mail: kiky.nurse@gmail.com
}

\begin{abstract}
Fire extinguisher is one of the active fire protection system that is used to extinguish fires are still small and used in emergencies, so as to prevent that no larger fires that cause harm and even fatalities. The aim of this study was to evaluate the installation of fire extinguisher in a fire emergency response system in the building surgical at Dr. Soetomo Hospital. This type of this study is evaluative research. Data were collected through observation, and measurement. Variables studied, namely the installation of fire extinguisher. Technique of analysis in this study is to use comparative approach to determine the suitability of the installation of a fire extinguisher that compared with Permenakertrans No. PER.04/MEN/1980. The approach taken were to semi quantitative to see how large the proportion of the suitability of the installation of a fire extinguisher in the surgical building at Dr. Soetomo Hospital. The results showed that at the Dr. Soetomo Hospital have fire emergency response system and has been applied. Installation fire extinguishers in the surgical building at Dr. Soetomo Hospital generally not meet the requirements of Permenakertrans No. PER.04/MEN/1980. There still is a fire extinguisher in the surgical building kind of halon in Bogenvil, Cempaka, Gladiol, Herbra and Nusa Indah. There is a fire extinguisher expired, in the surgical building at Cempaka, Dahlia, Flamboyan and Hebra.
\end{abstract}

Keywords: portable fire extinguisher, surgical building, Dr. Soetomo hospital

\begin{abstract}
ABSTRAK
Alat pemadam api ringan merupakan salah satu dari sistem proteksi kebakaran aktif yang digunakan untuk memadamkan kebakaran yang masih kecil dan digunakan dalam keadaan emergensi, sehingga dapat mencegah kebakaran agar tidak lebih besar yang menimbulkan kerugian bahkan korban jiwa. Tujuan dari penelitian ini adalah untuk mengevaluasi pemasangan alat pemadam api ringan dalam sistem tanggap darurat kebakaran di gedung bedah RSUD Dr. Soetomo Surabaya. Jenis penelitian ini adalah penelitian evaluatif. Data penelitian dikumpulkan dengan observasi, dan pengukuran. Variabel yang diteliti, yaitu pemasangan alat pemadam api ringan. Teknik analisis dalam penelitian ini adalah dengan mengunakan pendekatan komparatif untuk mengetahui kesesuaian pemasangan alat pemadam api ringan yang dibandingkan dengan Permenakertrans No. PER.04/MEN/1980. Pendekatan yang dilakukan adalah secara semi kuantitatif untuk melihat seberapa besar proposi kesesuaian pemasangan alat pemadam api ringan di gedung bedah RSUD Dr. Soetomo Surabaya. Hasil penelitian menunjukkan bahwa di RSUD Dr. Soetomo memiliki sistem tanggap darurat kebakaran dan sudah diterapkan. Pemasangan alat pemadam api ringan di gedung bedah RSUD Dr. Soetomo secara umum belum memenuhi persyaratan Permenakertrans No. PER.04/MEN/1980. Terdapat alat pemadam api ringan jenis halon di gedung bedah Bogenvil, Cempaka, Gladiol, Herbra dan Nusa Indah. Terdapat alat pemadam api ringan yang sudah kedaluwarsa yaitu di gedung bedah, Cempaka, Dahlia, Flamboyan dan Hebra.
\end{abstract}

Kata kunci: APAR, gedung bedah, RSUD Dr. Soetomo

\section{PENDAHULUAN}

Undang-undang No 44 Tahun 2009 menyatakan bahwa "Rumah Sakit adalah institusi pelayanan kesehatan yang menyelenggarakan pelayanan kesehatan perorangan secara paripurna yang menyediakan pelayanan rawat inap, rawat jalan, dan gawat darurat". Menurut World Health Organization (WHO), Rumah Sakit merupakan bagian integral dari organisasi sosial dan medis yang berfungsi untuk menyediakan perawatan kesehatan bagi penduduk dengan sarana yang lengkap, baik kuratif dan preventif yang dapat menjangkau pelayanan kesehatan keluarga dan lingkungan. Undang-undang No 44 tahun 2009 menyebutkan bahwa pendirian Rumah Sakit bertujuan memberikan perlindungan terhadap keselamatan pasien, masyarakat, lingkungan rumah sakit dan sumber daya manusia di rumah sakit. Disisi lain untuk kepentingan akreditasi rumah sakit ditetapkan bahwa setiap rumah sakit harus memiliki Hospital Disaster Plan secara tertulis. 
Hospital Disaster Plan dibuat untuk penanggulangan bencana, baik bencana eksternal maupun bencana internal Rumah Sakit. Selain persiapan untuk penanganan bencana eksternal rumah sakit, juga harus dipersiapkan penanganan bencana internal rumah sakit. Bencana internal rumah sakit adalah bencana yang terjadi di dalam lingkungan rumah sakit. Adanya hospital disaster plan, apabila terjadi bencana internal rumah sakit, maka kerugian material yang diakibatkan oleh bencana internal tersebut diharapkan dapat seminimal mungkin. Rumah sakit yang selalu melakukan pemberdayaan petugas terhadap bencana akan menimbulkan kemandirian bila suatu saat timbul bencana di lingkungan internal rumah sakit. Selain itu, operasional rumah sakit tetap berjalan seperti biasanya. Bilamana terjadi kelumpuhan sistem maka kelumpuhan ini akan cepat teratasi (Supriyanto dan Suhariono, 2015).

Peristiwa bencana internal yang terjadi di dalam lingkungan rumah sakit, salah satunya adalah kejadian kebakaran yang terjadi di lingkungan rumah sakit. Bencana kebakaran selain menyebabkan kerugian materiil juga menelan korban jiwa. Maka dari itulah pentingnya Sistem Tanggap Darurat Rumah Sakit. Tanggap darurat adalah tindakan segera untuk mengatasi kebakaran yang terjadi dengan mengerahkan sumber daya yang tersedia, sebelum bantuan dari luar datang. Untuk menghadapi kebakaran, perlu disusun organisasi tanggap darurat yang melibatkan semua unsur terkait dengan operasi atau kegiatan (Ramli, 2010).

Pemasangan alat pemadam api ringan (APAR) merupakan bagian dari sistem tanggap darurat kebakaran. Rumah sakit perlu dilengkapi dengan pemasangan APAR di setiap lantai dan ruangan yang mengandung risiko kebakaran. Selain APAR. Alat pemadam api ringan merupakan salah satu dari sistem proteksi kebakaran aktif yang merupakan bagian dari sistem tanggap darurat kebakaran digunakan untuk memadamkan kebakaran yang masih kecil dan digunakan dalam keadaan emergensi. Sehingga dapat mencegah atau mengatasi kebakaran agar tidak lebih besar yang menimbulkan kerugian bahkan korban jiwa.

Menurut Ramli (2010), rumah sakit merupakan tempat kerja yang rawan kebakaran. Kasus kebakaran cukup sering terjadi di tempat kerja termasuk rumah sakit, contohnya kasus kebakaran di Rumah Sakit Kabupaten Klaten pada tanggal 12 November 2009, kebakaran terjadi di gudang obat akibat hubungan pendek listrik. Tanggal 29 Juli 2009
Rumah Sakit Asih, Serang, mengalami kebakaran akibat hubungan pendek arus listrik pada trafo. Sejumlah pasien sempat dievakuasi ke Rumah Sakit terdekat. Rumah Sakit Umum (RSU) Dr. Sardjito Yogyakarta juga pernah mengalami kebakaran pada tanggal 7 Agustus 2007. Meskipun tidak ada korban jiwa, namun pasien sempat mengalami kepanikan. Berdasarkan kasus-kasus tersebut dapat diketahui bahwa penyediaan sistem tangap darurat kebakaran pada bangunan merupakan hal yang sangat penting (Ramli, 2010).

RSUD Dr. Soetomo Surabaya telah berdiri sejak tanggal 29 Oktober 1938, yang beralamatkan di J1. Mayjend Prof. Dr. Moestopo No. 6-8. Tahun 1979 berdasarkan SK Menkes ditetapkan RSUD Dr. Soetomo sebagai rumah sakit kelas A dan dikenal sebagai rumah sakit pelayanan, pendidikan dan penelitian. Rumah Sakit Dr. Soetomo Surabaya menjadi rumah sakit milik pemerintah Propinsi Jawa Timur, dengan luas lahan seluruhnya \pm 16 hektar rumah sakit ini akan memberikan pelayanan kesehatan bagi masyarakat Surabaya dan Jawa Timur bahkan menjadi pusat rujukan pelayanan kesehatan bagi wilayah Indonesia bagian timur.

Rumah Sakit Dr. Soetomo Surabaya pernah terjadi bencana kebakaran pada bulan Februari 2014. Kebakaran terjadi di gedung irna bedah Herbra. Kebakaran ini terjadi karena petir menyambar panel oksigen yang berada di lantai atas gedung. Sudah terdapat penangkal petir di lantai paling atas gedung, karena kekuatan petir yang sangat kuat menyebabkan pipa kecil yang terdapat di lubang panel oksigen terbakar. Akibatnya tekanan oksigen dalam panel menyemprot dan menimbulkan percikan api.

Penyediaan APAR termasuk ke dalam sistem tangap darurat kebakaran yang merupakan hal penting untuk mengantisipasi adanya keadaan darurat yang disebabkan oleh kebakaran. Penerapan sistem tanggap darurat dalam hal ini pemasangan APAR, tidak harus menunggu terjadinya keadaan darurat kebakaran namun, sebelumnya harus dibuat untuk mengantisipasi adanya kebakaran dan untuk meminimalkan kerugian serta mencegah terjadinya korban jiwa. RSUD Dr. Soetomo Surabaya telah memiliki sistem tanggap darurat kebakaran salah satunya adalah telah di pasangnya sistem APAR pada tiap gedung Rumah Sakit. Setiap enam bulan sekali dilakukan evaluasi terhadap kelayakan fungsi dari APAR yang sudah ada. Sejauh ini belum pernah dilakukan evaluasi pemasangan APAR terhadap peraturan yang berlaku di Indonesia, yaitu Permenakertrans No. PER.04/MEN/1980. 
Oleh karena itu peneliti tertarik untuk mengadakan penelitian sehubungan dengan evaluasi pemasangan APAR dalam sistem tanggap darurat kebakaran di gedung bedah RSUD Dr. Soetomo Surabaya.

Tujuan dari penelitian ini adalah untuk mengidentifikasi kesesuaian pemasangan APAR di gedung bedah RSUD Dr. Soetomo Surabaya dibandingkan dengan standar Permenakertrans No. PER.04/MEN/1980.

\section{METODE}

Penelitian ini berjudul "Evaluasi Pemasangan APAR dalam Sistem Tanggap Darurat Kebakaran di Gedung Bedah RSUD Dr. Soetomo Surabaya”. Jenis penelitian ini adalah penelitian evaluatif. Teknik analisis dalam penelitian ini adalah dengan mengunakan pendekatan komparatif melalui observasi, pengukuran dan melakukan telaah dokumen untuk mengetahui kesesuaian pemasangan APAR yang dibandingkan dengan standar yang berlaku di Indonesia yaitu Permenakertrans No. PER.04/MEN/1980. Pendekatan yang dilakukan adalah secara semi kuantitatif untuk melihat seberapa besar proposi kesesuaian pemasangan APAR di gedung bedah RSUD Dr. Soetomo Surabaya. Objek dalam penelitian ini adalah pemasangan alat pemadam api ringan.

Penelitian ini dilaksanakan di gedung Rumah Sakit Dr. Soetomo Surabaya meliputi gedung bedah Aster, Bogenvil, Cempaka, Dahlia, Eidelweis, Flamboyan, Gladiol, Herbra dan Nusa Indah yang terletak di Mayjend Prof. Dr. Moestopo No. 6-8. Waktu penelitian dilakukan pada bulan September 2015 - Januari 2016. Variabel yang diteliti, yaitu; pemasangan alat pemadam api ringan.

Teknik pengumpulan data dilakukan dengan observasi lapangan dan pengukuran menggunakan lembar check list, metline dan termohygro untuk mengetahui dimensi pemasangan APAR serta suhu ruangan. Data sekunder diperoleh peneliti dari dokumen-dokumen rumah sakit terkait dengan pemasangan APAR, serta data-data pendukung mengenai organisasi tangap darurat RSUD Dr. Soetomo Surabaya, selain itu data sekunder juga didapat dari studi literatur mengenai standar atau peraturan yang berhubungan dengan standar pemasangan APAR.

Proses pengolahan data dalam penelitian ini dilakukan secara manual berdasarkan hasil observasi, dan pengukuran. Analisis yang akan dilakukan adalah analisis univariat yaitu menggambarkan pemasangan APAR yang ada di gedung bedah RSUD Dr. Soetomo Surabaya, kemudian dibandingkan dengan standar yang berlaku di Indonesia, yaitu Permenakertrans No. PER.04/MEN/1980. Setelah itu dilihat prosentase kesesuaian pemasangan APAR yang ada di gedung bedah RSUD Dr. Soetomo Surabaya.

\section{HASIL}

\section{Kebijakan Penanggulangan Darurat Kebakaran di RSUD Dr. Soetomo}

Kebijakan penanggulangan darurat kebakaan disusun supaya menjadi pola tanggap darurat kebakaran yang terpadu, sehingga menjadi panduan bagi para petugas agar di dalam pelaksanaan penanggulangan tanggap darurat kebakaran dapat berjalan dengan lancer, efektif dan efisien serta menghindari terjadinya kepanikan guna mencegah dilakukannya tindakan-tindakan yang salah yang dapat berakibat fatal atau menimbulkan kerugian yang lebih besar. Rumah Sakit Dr. Soetomo telah memiliki kebijakan dalam penanggulangan darurat kebakaran. Kebijakan tersebut terdapat tata laksana penanggulangan kebakaran serta struktur organisasi tanggap darurat kebakaran yang mencangkup tugas dan tanggung jawab setiap personalnya. Prinsip penanganan bencana internal seperti kebakaran, menggunakan pendekatan peningkatan ketahanan dan kemandirian masyarakat rumah sakit.

Manajemen Rumah Sakit dalam kondisi aman melakukan upaya pemberdayaan petugas RS, untuk itu bidang Diklat merencanakan dan melaksanakan diklat Keselamatan dan Kesehatan Kerja Rumah Sakit (K3RS) dan kewaspadaan bencana, meliputi transfer knowledge dan skill. Skill simulasi bencana dimanfaatkan sebagai momen monitoring dan evaluasi sarana pengendalian bencana. Melalui peningkatan ketahanan dan kemandirian petugas RS, diharapkan para personal mampu sepenuhnya mengatasi bencana yang terjadi di wilayah kerjanya. Ada beberapa kondisi tertentu di mana bencana tidak bisa diatasi secara tuntas (hanya sebagian teratasi), dalam kondisi ini RS akan memberi bantuan teknis (bantuan tim keamanan, IPS, sanitasi, dan lain-lain). Bilamana unit kerja atau instansi sama sekali tidak mampu mengatasinya, maka RS akan mengirim bantuan lebih besar meliputi bantuan teknis dan bantuan lain berupa human resource, administrasi atau manajerial, safety-environment hingga finansial. 
Apabila kondisi bencana tidak bisa dihentikan, unit kerja meminta bantuan pada manajemen rumah sakit. Bantuan yang diberikan bergantung pada besarnya bencana dan tingkat kemandirian penanganan oleh unit kerja.

Rumah sakit harus siap melakukan penanganan pasien termasuk kesiapan sistem untuk mendukung proses penanganan tersebut saat terjadi bencana. Sistem ini disusun berupa diberlakukannya struktur organisasi saat aktivasi sistem penanganan bencana oleh rumah sakit. Garis komunikasi yang dilaksanakan pada situasi bencana adalah: aktivasi sistem penanganan bencana RS; mobilisasi tim medik; mobilisasi tim manajemen; aktivasi pos komando; penggunaan media komunikasi yang ada yaitu radio medik, operator RS, supervisi IGD; peran dan tanggung jawab inti staf RS dan staf unit kerja, yang dilaksanakan oleh setiap orang sewaktu-waktu sesuai jabatan; tetap memberikan informasi terkini yang telah disetujui oleh Komando rumah sakit.

\section{Pemberdayaan Sumber Daya Manusia dan Peran Staf}

Rumah sakit senantiasa melaksanakan pemberdayaan sumber daya manusia (SDM) tentang knowledge, attitude, practice (KAP) Keselamatan dan Kesehatan Kerja Rumah Sakit (K3RS) dan kewaspadaan bencana. Pemberdayaan SDM melalui mekanisme diklat dan simulasi rutin minimal 1 tahun sekali di setiap building atau gedung atau instansi. Pemberdayaan ini dimaksudkan untuk menyamakan pemahaman atau pola fikir dan sebagai kesamaan pola tindakan bila terjadi bencana, sehingga tidak terjadi kepanikan serta tindakan yang di luar kontrol yang mengarah pada kerugian atau ketidakefisienan tindakan pertolongan. Masing-masing petugas dalam gedung secara mandiri mampu melakukan upaya penanganan sebelum bantuan datang.

Pemberdayaan juga terkait peran staf, dalam kondisi bencana staf akan mengambil peran dan memposisikan dirinya dalam penanganan bencana dengan menerapkan K3 yang telah dilatihkan. Peran staf berada pada garis komando di mana sebagai komando adalah atasan atau yang lebih senior baik jabatan maupun kompetensi tentang bencana. Dengan demikian komandan diharapkan bisa membawa staf ke tempat yang lebih aman. Staf dan pimpinan unit kerja memahami dan dapat menerapkan teori K3RS dan kewaspadaan bencana, sehinga paham dan bisa memposisikan diri dalam penugasan peran penanganan bencana.

\section{Karakteristik Gedung Irna Bedah RSUD Dr. Soetomo}

Klasifikasi bangunan gedung irna bedah RSUD Dr. Soetomo berdasarkan tingkat ketahanan terhadap api seperti yang diatur pada Peraturan Menteri Negara Pekerjaan Umum No.26/PRT/M/2008, termasuk dalam bangunan kelas A yaitu bangunan yang komponen struktur utamanya harus tahan terhadap api sekurang-kurangnya 3 jam. Klasifikasi bangunan berdasarkan tingkat potensi bahaya gedung bedah RSUD Dr. Soetomo termasuk bahaya kebakaran ringan.

Bahan untuk komponen struktur bangunan gedung irna bedah terdiri dari dinding, tiang, lantai dan atap. Dinding gedung bedah terbuat dari batu bata dan adukan semen yang setengah dari tinggi dinding dilapisi dengan lapisan keramik. Lantai terbuat dari beton dan adukan semen yang dilapisi ubin keramik. Serta atap terbuat dari genteng. Bahan lapis penutup untuk ruangan menggunakan tembok batu bata dan adukan semen yang setengah dari tinggi dinding dilapisi dengan keramik. Langit-langit dengan menggunakan gipsum. Kusen pintu dan jendela menggunakan bahan kayu, untuk daun pintu dan jendela menggunakan bahan kayu, alumunium dan kaca. Khusus bedah Flamboyan, Gladiol dan Herbra terdapat tangga darurat di dalam gedung terbuat dari beton dan adukan semen yang dilapisi ubin, sedangkan atap gedung terbuat dari beton dan adukan semen.

Gedung bedah pada masing-masing ruangan terdapat ruang Kepala Ruang, ruang tata usaha, ruang perawat, nurse station, farmasi, ruang pertemuan, mushola, ruang ganti, ruang tunggu, ruang penyimpanan tabung $\mathrm{O}_{2}$, dapur serta kamar mandi/wc pasien dan keluarga serta kamar mandi/wc perawat. Ruang perawatan antar pasien di gedung bedah disekat oleh sekat tembok terbuat dari batu bata dan adukan semen, serta disekat pula oleh tirai. Di dalam ruang bedah memiliki isi ruangan yaitu, tempat duduk (sofa, kursi kayu, kursi plastik, kursi besi), meja kayu dan meja kaca, lemari kaca penyimpanan data, ATK, juga peralatan elektronik kantor (tv, komputer), kulkas, tempat tidur pasien, kompor, tabung yang berisi gas oksigen dan gas elpij, dan juga rak penyimpanan obat.

\section{Pemasangan Alat Pemadam Api Ringan}

Alat pemadam api ringan (APAR) yang ada di gedung irna bedah RSUD Dr. Soetomo berisi gas cair yang merupakan turunan dari gas halon 
dan memiliki kapasitas $6 \mathrm{~kg}$ dan $7 \mathrm{~kg}$. Kelebihan apar jenis gas cair adalah bersifat bersih tidak meninggalkan residu, tidak merusak lapisan ozon atau non halon non $\mathrm{CFC}$, ramah lingkungan (clean agent) dan lebih cepat memadamkan api. Material tabung APAR tersebut terbuat dari bahan mild steel dan dilapisi dengan cat berwarna merah. Rating/kelas kebakaran yang dapat ditanggulangi yaitu kelas A, B dan C. Pemasangan APAR telah dilengkapi dengan tanda dan label cara penggunaan APAR. Pemeriksaan berkala APAR dilakukan setiap 6 bulan sekali, oleh Departemen Rumah Tangga. Pemeriksaan yang dilakukan meliputi pressure, handle, selang nozzle, dan kondisi tabung. Laporan pemeriksaan langsung di input di komputer dan tidak ada label pemeriksaan pada APAR.

\section{Gedung Bedah Aster}

Jumlah box APAR di gedung bedah Aster terdapat 4 buah, namun dari 4 box yang ada hanya berisi 2 buah APAR. Jenis APAR yang terdapat di gedung bedah Aster adalah 3 berjenis gas cair dengan berat $7 \mathrm{~kg}$ dan 1 berjenis celetron dengan berat $5 \mathrm{~kg}$.

Hasil evaluasi pemasangan APAR di gedung bedah Aster adalah sebagai berikut; kondisi pressure APAR normal, tidak kedaluwarsa; APAR ditempatkan pada posisi yang mudah dilihat, mudah dicapai dan diambil; penempatan antara APAR yang satu dengan lainnya atau kelompok satu dengan lainnya $\leq 15$ meter; setiap alat pemadam api ringan ditempatkan dalam lemari atau peti (box); peti (box) APAR ada yang dikunci, bagian depannya terdapat safety glass dengan tebal maximum $2 \mathrm{~mm}$; pemasangan APAR rata-rata berada pada ketinggian $1,5 \mathrm{~m}-1,6 \mathrm{~m}$; suhu ruangan $31,8^{\circ} \mathrm{C}$; APAR tidak berlubang-lubang atau cacat karena karat; terdapat tanda APAR; instruksi penggunaan APAR terletak pada bagian samping APAR; masing-masing sisinya berukuran $29 \mathrm{~cm}$, lebar tulisan APAR $1,5 \mathrm{~cm}$ dan panjang tanda panah $4,5 \mathrm{~cm}$.

\section{Gedung Bedah Bogenvil}

Jumlah box APAR di gedung bedah Boenvil terdapat 6 buah, dan jumlah APAR juga 6 buah APAR. Jenis APAR yang terdapat di gedung bedah Bogenvil sebanyak 3 buah APAR berjenis CF 21 dengan berat $5 \mathrm{~kg}$ dan $7 \mathrm{~kg}, 3$ buah APAR berjenis gas cair dengan berat APAR $5 \mathrm{~kg}$.

Hasil evaluasi pemasangan APAR di gedung bedah Bogenvil adalah sebagai berikut; pressure normal, tidak kadaluarsa; terdapat pemasangan yang
$180 \mathrm{~cm}$ dari lantai, akan kesulitan untuk dicapai; penempatan antara APAR yang satu dengan lainnya atau kelompok satu dengan lainnya $\leq 15$ meter; setiap alat pemadam api ringan ditempatkan dalam lemari atau peti (box); peti (box) APAR ada yang dikunci, bagian depannya terdapat safety glass dengan tebal maximum $2 \mathrm{~mm}$; pemasangan APAR rata-rata berada pada ketinggian 1,5 m-1,6 m; suhu ruangan $29,8^{\circ} \mathrm{C}$; APAR tidak berlubang-lubang atau cacat karena karat; terdapat tanda; instruksi penggunaan APAR terletak pada bagian samping APAR; masing-masing sisinya berukuran $29 \mathrm{~cm}$, lebar tulisan APAR 1,5 cm dan panjang tanda panah $4,5 \mathrm{~cm}$.

\section{Gedung Bedah Cempaka}

Jumlah box APAR di gedung bedah Cempaka terdapat 5 buah, dan jumlah APAR juga 5 buah APAR. Jenis APAR yang terdapat di gedung bedah Cempaka adalah gas 3 gas cair dengan berat $5 \mathrm{~kg} 2$ buah APAR diantaranya dalam kondisi kedaluwarsa, 1 buah APAR jenis BCF dengan berat $7 \mathrm{~kg}$ dan 1 buah APAR jenis powder dengan berat $6 \mathrm{~kg}$.

Hasil evaluasi pemasangan APAR di gedung bedah Cempaka adalah sebagai berikut; pressure normal, ada 2 buah APAR yang kedaluwarsa; APAR ditempatkan pada posisi yang mudah dilihat, mudah dicapai dan diambil; penempatan antara APAR yang satu dengan lainnya atau kelompok satu dengan lainnya $\leq 15$ meter; setiap alat pemadam api ringan ditempatkan dalam lemari atau peti (box); peti (box) APAR ada yang dikunci, bagian depannya terdapat safety glass dengan tebal maximum $2 \mathrm{~mm}$; pemasangan APAR rata-rata berada pada ketinggian $1,6 \mathrm{~m}-1,7 \mathrm{~m}$; suhu ruangan $30^{\circ} \mathrm{C}$.

APAR tidak berlubang-lubang atau cacat karena karat; terdapat tanda; instruksi penggunaan APAR terletak pada bagian samping APAR; masing-masing sisinya berukuran $29 \mathrm{~cm}$, lebar tulisan APAR $1,5 \mathrm{~cm}$ dan panjang tanda panah $4,5 \mathrm{~cm}$.

\section{Gedung Bedah Dahlia}

Jumlah box APAR di gedung bedah Dahlia terdapat 7 buah, dan jumlah APAR juga 6 buah APAR. Jenis APAR yang terdapat di gedung bedah Dahlia kesemuanya berupa gas cair dengan berat $5 \mathrm{~kg}, 5$ buah APAR dan 1 buah APAR dengan berat $7 \mathrm{~kg}$. Kesemua APAR yang terdapat di gedung bedah Dahlia dalam kondisi kedaluwarsa.

Hasil evaluasi pemasangan APAR di gedung bedah Dahlia adalah sebagai berikut; pressure normal, semua APAR dalam kondisi kadaluarsa; 
APAR ditempatkan pada posisi yang mudah dilihat, mudah dicapai dan diambil; penempatan antara APAR yang satu dengan lainnya atau kelompok satu dengan lainnya $\leq 15$ meter; setiap alat pemadam api ringan ditempatkan dalam lemari atau peti (box); peti (box) APAR ada yang dikunci, bagian depannya terdapat safety glass dengan tebal maximum $2 \mathrm{~mm}$; pemasangan APAR rata-rata berada pada ketinggian $1,6 \mathrm{~m}$; suhu ruangan $31,7^{\circ} \mathrm{C}$; APAR tidak berlubanglubang atau cacat karena karat; terdapat tanda; instruksi penggunaan APAR terletak pada bagian samping APAR; masing-masing sisinya berukuran $29 \mathrm{~cm}$, lebar tulisan APAR $1,5 \mathrm{~cm}$ dan panjang tanda panah $4,5 \mathrm{~cm}$.

\section{Gedung Bedah Eidelweis}

Jumlah box APAR di gedung bedah Eidelweis terdapat 3 buah, dan jumlah APAR terdapat 4 buah APAR (1 buah berada di gudang). Jenis APAR yang terdapat di gedung bedah Eidelweis kesemuanya berupa gas cair dengan berat $5 \mathrm{~kg}$.

Hasil evaluasi pemasangan APAR di gedung bedah Eidelweis adalah sebagai berikut; pressure normal, APAR tidak kedaluwarsa; APAR ditempatkan pada posisi yang mudah dilihat, mudah dicapai dan diambil; penempatan antara APAR yang satu dengan lainnya atau kelompok satu dengan lainnya $\leq 15$ meter; setiap alat pemadam api ringan ditempatkan dalam lemari atau peti (box); peti (box) APAR ada yang dikunci, bagian depannya terdapat safety glass dengan tebal maximum $2 \mathrm{~mm}$; pemasangan APAR rata-rata berada pada ketinggian $1,6 \mathrm{~m}$; suhu ruangan $32,6^{\circ} \mathrm{C}$; APAR tidak berlubanglubang atau cacat karena karat; terdapat tanda; instruksi penggunaan APAR terletak pada bagian samping APAR; masing-masing sisinya berukuran $29 \mathrm{~cm}$, lebar tulisan APAR $1,5 \mathrm{~cm}$ dan panjang tanda panah $4,5 \mathrm{~cm}$.

\section{Gedung Bedah Flamboyan}

Jumlah box APAR di gedung bedah Flamboyan terdapat 5 buah, dan jumlah APAR terdapat 5 buah APAR. Jenis APAR yang terdapat di gedung bedah Flamboyan kesemuanya berupa gas cair dengan berat $5 \mathrm{~kg}$.

Hasil evaluasi pemasangan APAR di gedung bedah Flamboyan adalah sebagai berikut; pressure normal, sebuah APAR dalam kondisi kedaluwarsa; APAR ditempatkan pada posisi yang mudah dilihat, mudah dicapai dan diambil; penempatan antara APAR yang satu dengan lainnya atau kelompok satu dengan lainnya $\leq 15$ meter; setiap alat pemadam api ringan ditempatkan dalam lemari atau peti (box); peti (box) APAR ada yang dikunci, bagian depannya terdapat safety glass dengan tebal maximum $2 \mathrm{~mm}$; pemasangan APAR rata-rata berada pada ketinggian $1,5 \mathrm{~m}$; suhu ruangan $32,1^{\circ} \mathrm{C}$; APAR tidak berlubanglubang atau cacat karena karat; terdapat tanda; instruksi penggunaan APAR terletak pada bagian samping APAR; masing-masing sisinya berukuran $29 \mathrm{~cm}$, lebar tulisan APAR $1,5 \mathrm{~cm}$ dan panjang tanda panah $4,5 \mathrm{~cm}$.

\section{Gedung Bedah Gladiol}

Jumlah box APAR di gedung bedah Gladiol terdapat 4 buah, dan jumlah APAR terdapat 4 buah APAR. Jenis APAR yang terdapat di gedung bedah Gladiol berupa 3 buah APAR berjenis gas cair dengan berat $5 \mathrm{~kg}$ dan sebuah APAR berjenis BCF dengan berat $5 \mathrm{~kg}$.

Hasil evaluasi pemasangan APAR di gedung bedah Gladiol adalah sebagai berikut; pressure normal, APAR tidak kedaluwarsa; APAR ditempatkan pada posisi yang mudah dilihat, mudah dicapai dan diambil; penempatan antara APAR yang satu dengan lainnya atau kelompok satu dengan lainnya $\leq 15$ meter; setiap alat pemadam api ringan ditempatkan dalam lemari atau peti (box); peti (box) APAR ada yang dikunci, bagian depannya terdapat safety glass dengan tebal maximum $2 \mathrm{~mm}$; pemasangan APAR rata-rata berada pada ketinggian $1,5 \mathrm{~m}-1,6 \mathrm{~m}$; suhu ruangan $32^{\circ} \mathrm{C}$; APAR tidak berlubang-lubang atau cacat karena karat; terdapat tanda; instruksi penggunaan APAR terletak pada bagian samping APAR; masing-masing sisinya berukuran $29 \mathrm{~cm}$, lebar tulisan APAR $1,5 \mathrm{~cm}$ dan panjang tanda panah $4,5 \mathrm{~cm}$.

\section{Gedung Bedah Hebra}

Jumlah box APAR di gedung bedah Herbra terdapat 6 buah, dan jumlah APAR terdapat 6 buah APAR. Jenis APAR yang terdapat di gedung bedah Herbra 5 buah APAR berjenis gas cair dengan berat $5 \mathrm{~kg}$ dan sebuah APAR berjenis CF 21 dengan berat $5 \mathrm{~kg}$ dalam kondisi kedaluwarsa.

Hasil evaluasi pemasangan APAR di gedung bedah Herbra adalah sebagai berikut; pressure normal, 1 buah APAR kedaluwarsa; APAR ditempatkan pada posisi yang mudah dilihat, mudah dicapai dan diambil; penempatan antara APAR yang satu dengan lainnya atau kelompok satu dengan lainnya $\leq 15$ meter; setiap alat pemadam api ringan 
ditempatkan dalam lemari atau peti (box); peti (box) APAR ada yang dikunci, bagian depannya terdapat safety glass dengan tebal maximum $2 \mathrm{~mm}$; pemasangan APAR rata-rata berada pada ketinggian $1,5 \mathrm{~m}-1,6 \mathrm{~m}$; suhu ruangan $32,3^{\circ} \mathrm{C}$; APAR tidak berlubang-lubang atau cacat karena karat; terdapat tanda; instruksi penggunaan APAR terletak pada bagian samping APAR; masing-masing sisinya berukuran $29 \mathrm{~cm}$, lebar tulisan APAR $1,5 \mathrm{~cm}$ dan panjang tanda panah $4,5 \mathrm{~cm}$.

\section{Gedung Bedah Nusa Indah}

Jumlah box APAR di gedung bedah Nusa Indah terdapat 6 buah, dan jumlah APAR terdapat 6 buah APAR. Jenis APAR yang terdapat di gedung bedah Nusa Indah adalah 5 buah APAR berjenis gas cair dengan berat $5 \mathrm{~kg}$ dan 1 buah APAR berjenis CF 21 dengan berat $5 \mathrm{~kg}$.

Hasil evaluasi APAR di gedung bedah Nusa Indah adalah sebagai berikut; pressure normal, APAR tidak kedaluwarsa; APAR ditempatkan pada posisi yang mudah dilihat, mudah dicapai dan diambil; penempatan antara APAR yang satu dengan lainnya atau kelompok satu dengan lainnya $\leq 15$ meter; setiap alat pemadam api ringan ditempatkan dalam lemari atau peti (box); peti (box) APAR ada yang dikunci, bagian depannya terdapat safety glass dengan tebal maximum $2 \mathrm{~mm}$; pemasangan APAR rata-rata berada pada ketinggian $1,5 \mathrm{~m}-1,6 \mathrm{~m}$; suhu ruangan $30,2^{\circ} \mathrm{C}$; APAR berkarat di bagian bawah, dan box APAR ada genangan air; terdapat tanda; instruksi penggunaan APAR terletak pada bagian samping APAR; masing-masing sisinya berukuran $29 \mathrm{~cm}$, lebar tulisan APAR $1,5 \mathrm{~cm}$ dan panjang tanda panah $4,5 \mathrm{~cm}$.

Tabel 1 dapat diketahui bahwa kesemua ruang bedah di RSUD Dr. Soetomo Surabaya

Tabel 1. Hasil Evaluasi APAR di Gedung Bedah RSUD Dr. Soetomo

\begin{tabular}{llcc}
\hline \multirow{2}{*}{ No } & \multirow{2}{*}{ Gedung Bedah } & \multicolumn{2}{c}{ Tingkat Kesesuaian } \\
\cline { 3 - 4 } & & Sesuai (\%) & Tidak (\%) \\
\hline 1 & Aster & 72,7 & 27,3 \\
2 & Bogenvil & 63,7 & 36,3 \\
3 & Cempaka & 63,7 & 36,3 \\
4 & Dahlia & 63,7 & 36,3 \\
5 & Eidelweis & 72,7 & 27,3 \\
6 & Flamboyan & 63,7 & 36,3 \\
7 & Gladiol & 72,7 & 27,3 \\
8 & Herbra & 72,7 & 27,3 \\
9 & Nusa Indah & 63,7 & 36,3 \\
\hline
\end{tabular}

pemasangan APAR belum 100\% memenuhi standar Permenakertrans No. 04 Tahun 1980.

\section{PEMBAHASAN}

\section{Risiko Kebakaran Gedung Bedah RSUD Dr. Soetomo}

Menurut Peraturan Menteri Pekerjaan Umum No. 26/PRT/M/2008 tentang Persyaratan Teknis Sistem Proteksi Kebakaran pada Bangunan Gedung dan Lingkungan, berdasar ketahanan struktur bangunan terhadap api Rumah Sakit adalah tipe bangunan kelas A, yaitu bangunan yang komponen struktur utamanya harus tahan terhadap api sekurang-kurangnya 3 jam. Berdasarkan data hasil penelitian terhadap bangunan gedung bedah RSUD Dr. Soetomo, bangunan tersebut diklasifikasikan menurut tingkat ketahanan struktur utamanya terhadap api merupakan bangunan kelas A karena termasuk bangunan rumah sakit, seperti yang diatur pada Peraturan Menteri Pekerjaan Umum No. 26/ PRT/M/2008 tentang Persyaratan Teknis Sistem Proteksi Kebakaran pada Bangunan Gedung dan Lingkungan

Klasifikasi bahaya hunian menurut SNI 033989-2000, Rumah Sakit termasuk memiliki risiko kebakaran ringan. Hesna et al (2009), menyatakan penyebab kebakaran di rumah sakit antara lain disebabkan oleh sambungan pendek arus listrik, penggunaan peralatan listrik, penggunaan tabung gas bertekanan, serta penggunaan berbagai macam bahan kimia baik cair maupun padat yang bersifat flammable, korosif, dan harmful. Sumber potensi bahaya kebakaran tersebut kemudian membuat rumah sakit menjadi bangunan yang memiliki risiko kebakaran. Terlebih lagi bahwa sebagian penghuni rumah sakit merupakan orang sakit yang tidak mampu melayani dan menyelamatkan dirinya sendiri apabila terjadi kebakaran.

Sedangkan klasifikasi kebakaran menurut Permenakertrans No. Per.04/MEN/1980, tentang Syarat-syarat Pemasangan dan Pemeliharaan Alat Pemadam Api Ringan, klasifikasi kebakaran di gedung bedah RSUD Dr. Soetomo adalah kelas A, B dan C. Termasuk klasifikasi kelas A, B dan C dikarenakan di gedung bedah RSUD Dr. Soetomo terdapat benda padat, cairan kimia maupun gas yang mudah terbakar seperti alkohol dan tabung berisi oksigen yang terdapat di semua ruang bedah, serta terdapat tabung berisi LPG di dapur, selain itu di gedung bedah juga terdapat peralatan listrik, 
elektronik seperti TV, kulkas, dan komputer yang dapat berisiko terjadi kebakaran terdapat pula.

\section{Alat Pemadam Api Ringan (APAR)}

Pemasangan APAR dievaluasi berdasarkan Peraturan Menteri Tenaga Kerja dan Transmigrasi No. 04 Tahun 1980 tentang Syarat-syarat Pemasangan dan Pemeliharaan Alat Pemadam Api Ringan. Berdasarkan hasil pembahasan mengenai risiko kebakaran pada gedung irna bedah RSUD Dr. Soetomo didapatkan hasil bahwa gedung tersebut memiliki risiko kebakaran ringan dengan kelas kebakaran A, B dan C. Jenis APAR yang paling efektif untuk kelas kebakaran tersebut adalah APAR yang berjenis gas cair/halon free. Ditemukan APAR jenis BCF berisi bromide, clorine, fluorine dan CF 21 yang berisi clorine dan fluorine di irna bedah RSUD Dr. Soetomo. Penggunaan APAR berjenis halon masih banyak ditemukan di berbagai tempat. Hasil penelitian yang dilakukan oleh Angela (2006), menyebutkan bahwa di PT. Indogravure ditemukan APAR jenis BCF dan $\mathrm{CF}$. Bahan tersebut akan bereaksi membentuk gas halon. Halon merupakan bahan kimia gas pemadam api terbaik dan bersih, cocok untuk kebakaran kelas A,B dan $\mathrm{C}$, namun APAR yang berisi gas halon telah dilarang peredarannya di dunia karena merusak lapisan ozon. Ditemukan juga bahwa halon apabila terkena api akan menimbulkan racun yang bernama bromofsgene dan berbahaya bagi manusia. Pelarangan penggunaan halon tersebut dilakukan oleh seluruh dunia dan penghentian produksinya sejak tahun 1996. Sedangkan di Indonesia larangan penggunaan halon ini berlaku Januari 2005 oleh Badan Lingkungan Hidup Indonesia dan sesuai Keputusan Menteri Perindustrian dan Perdagangan No.110 tahun 1998 tentang Larangan Memproduksi dan Memperdagangkan Bahan Perusak Lapisan Ozon Serta Memproduksi dan Memperdagangkan Barang Baru yang Mengunakan Bahan Perusak Lapisan Ozon.

Pemeriksaan berkala APAR dilakukan setiap 6 bulan sekali, oleh Departemen Rumah Tangga. Pemeriksaan yang dilakukan meliputi pemeriksaan kondisi pressure, handle, selang nozzle, dan kondisi tabung. Rata-rata pemasangan APAR di berbagai tempat belum memenuhi persyaratan berdasarkan Permenakertrans No. PER.04/MEN/1980. Arazzy et al (2010), menyebutkan bahwa di RS Umum Kardinah Kota Tegal yang masih berfungsi dengan kondisi baik dan telah sesuai dengan standar sebesar
$72 \%$, tetapi untuk pemeriksaan belum sesuai dengan standar karena pemeriksaan APAR dilaksanakan satu tahun sekali. Begitu juga dengan Rumah Sakit Dr. Sobirin, pemeriksaan dilakukan setahun sekali dan tidak ditemukan kartu pemeriksaan.

Rumah Sakit Dr. Soetomo laporan hasil pemeriksaan APAR langsung di input di komputer dan tidak ada label pemeriksaan yang dipasang pada APAR. Label hasil pemeriksaan perlu dipasang pada APAR, karena dengan dipasangnya label pemeriksaan orang yang akan menggunakan APAR tersebut tahu bagaimana kondisi APAR dan layak digunakan atau tidaknya APAR. Firdani et al (2014), mengemukakan bahwa APAR harus di lakukan pemeriksaan secara rutin. Petugas yang melakukan pemeriksaan harus menyimpan data dari semua hasil pemeriksaan APAR, termasuk tindakan korektif yang dilakukan. Pemeriksaan dilakukan sekurangkurangnya sebulan sekali dan setelah pemeriksaan petugas yang melakukan pemeriksaan mencatat tanggal, nama petugas yang melakukan pemeriksaan dan hasil pemeriksaan. Hasil pemeriksaan harus dipelihara melalui etiket atau label yang ditempelkan pada APAR, selain itu data hasil inspeksi juga harus didokumentasikan melalui daftar pemeriksaan secara tertulis maupun lewat media elektronik yang menjamin arsip tersimpan permanen.

Hasil evaluasi pemeriksaan APAR menunjukkan bahwa gedung irna bedah belum $100 \%$ memenuhi standar Permenakertrans No. 04 Tahun 1980, salah satunya adalah mengenai instruksi penggunaan APAR. Instruksi penggunaan APAR sangat perlu dipasang pada bagian depan, hal ini agar memudahkan orang yang akan menggunakan APAR dapat melihat dengan jelas instruksi tersebut. Namun kondisi di gedung bedah RSUD Dr. Soetomo instruksi penggunaan APAR diletakkan di samping box APAR, sehingga orang dari sisi berlawanan tidak dapat melihat instruksi tersebut.

Pemasangan APAR di gedung bedah RSUD Dr. Soetomo rata-rata berada pada ketinggian 1,5 m-1,6 $\mathrm{m}$, bahkan ada yang berada diketinggian 1,8 $\mathrm{m}$. Hal tersebut belum memenuhi syarat pemasangan APAR yang diatur dalam Permenakertrans No. 04 tahun 1980. Hal ini dikarenakan pemasangan dilakukan oleh Departemen Rumah Tangga, padahal dari pihak K3RS sudah mengusulkan tinggi pemasangan APAR dari lantai adalah 1,2 m. Pemasangan APAR yang melebihi tinggi dari standar yang dianjurkan, dikhawatirkan APAR akan sulit dijangkau saat keadaan darurat, karena pemasangan yang terlalu tinggi. 
Terdapat APAR dalam kondisi kedaluwarsa, yaitu di gedung bedah Cempaka terdapat 2 buah APAR kedaluwarsa, di gedung bedah Dahlia semua APAR dalam kondisi kedaluwarsa, dan bedah Flamboyan terdapat 1 buah APAR dalam kondisi kedaluwarsa. Terdapat pula APAR berkarat di bagian bawah serta terdapat genangan air pada box APAR bagian bawah. Menurut NFPA 10, APAR dalam kondisi kedaluwarsa dan berkarat dilarang penggunaannya, karena APAR kedaluwarsa maupun berkarat merugikan bagi pengguna. Oleh karenanya APAR kedaluwarsa maupun berkarat tidak memiliki performa yang sesuai dengan spesifikasi aslinya. Bahan yang ada di dalam APAR bisa jadi tidak berfungsi sebagaimana yang diharapkan sehingga tidak efektif memadamkan api. Selain itu biasanya juga terjadi penurunan pressure yang menyebabkan APAR tidak bisa menjangkau titik api secara maksimal.

Sanjaya dan Maria (2015), menyatakan bahwa pemenuhan standar tidak dapat dikesampingkan, mengingat apabila benar-benar terjadi kebakaran dan masih terdapat komponen yang tidak memenuhi standar, maka mengakibatkan kerugian yang besar bahkan korban jiwa. Syarat pemasangan APAR yang belum memenuhi standar sebaiknya segera ditindaklanjuti untuk mengoptimalkan kesiapan penanggulangan bencana kebakaran di rumah sakit, karena fungsi dari APAR adalah untuk memadamkan kebakaran yang masih kecil dan digunakan dalam keadaan emergensi, sehingga dapat mencegah atau mengatasi kebakaran agar tidak lebih besar yang menimbulkan kerugian bahkan korban jiwa

Klasifikasi kebakaran di gedung bedah Aster, Bogenvil, Cempaka, Dahlia, Eidelweis, Flamboyan, Gladiol, Herbra dan Nusa Indah adalah kelas A, B dan C. Luas area yang dapat dilindungi APAR di semua ruangan masing-masing adalah $176,625 \mathrm{~m}^{2}$ untuk bahaya kebakaran ringan, dengan perhitungan sebagai berikut:

\section{Radius perlindungan APAR}

$=\mu \times \mathrm{r}^{2}$

$=3,14 \times\left(\frac{15}{2}\right)^{2}$

$=176,625 \mathrm{~m}^{2}$

Jumlah APAR $=\frac{\text { Luas }}{\text { luas perlindungan APAR }}$

Pemenuhan kebutuhan APAR di setiap ruang bedah sudah memenuhi perhitungan kebutuhan. Hal ini disebabkan karena pemenuhan APAR berdasarkan
Tabel 2. Perhitungan Jumlah Kebutuhan APAR di Gedung Bedah RSUD Dr. Soetomo Surabaya

\begin{tabular}{lccc}
\hline \multicolumn{1}{c}{ Lokasi } & Luas & Hasil & $\begin{array}{c}\text { Jumlah } \\
\text { Nyata }\end{array}$ \\
\hline Aster & $356 \mathrm{~m}^{2}$ & 3 APAR & 4 APAR \\
Bogenvil & $348 \mathrm{~m}^{2}$ & 2 APAR & 6 APAR \\
Cempaka & $350 \mathrm{~m}^{2}$ & 2 APAR & 5 APAR \\
Dahlia & $352 \mathrm{~m}^{2}$ & 2 APAR & 7 APAR \\
Eidelweis & $330 \mathrm{~m}^{2}$ & 2 APAR & 3 APAR \\
Flamboyan & $376 \mathrm{~m}^{2}$ & 3 APAR & 5 APAR \\
Gladiol & $376 \mathrm{~m}^{2}$ & 3 APAR & 4 APAR \\
Herbra & $376 \mathrm{~m}^{2}$ & 3 APAR & 6 APAR \\
Nusa Indah & $660 \mathrm{~m}^{2}$ & 4 APAR & 6 APAR \\
\hline
\end{tabular}

pertimbangan pihak K3RS, di mana jumlah tersebut berdasarkan pada titik risiko kebakaran yang ada pada setiap gedung bedah, serta setiap gedung bedah memiliki luas ruangan yang berbeda-beda.

\section{SIMPULAN}

Pemasangan dan jenis APAR yang digunakan di gedung bedah Rumah Sakit Umum Daerah Dr. Soetomo masih belum sesuai dengan Permenakertrans No. PER.04/MEN/1980. Masih terdapat APAR jenis halon yang digunakan di gedung bedah, tinggi pemasangan APAR yang belum sesuai, instruksi penggunaan APAR yang diletakkan di samping box APAR serta terdapat APAR yang sudah kedaluwarsa. Saran yang dapat diberikan antara lain; penggantian APAR BCF dan CF 21 di gedung bedah Bogenvil, Cempaka, Gladiol, Herbra dan Nusa Indah dengan APAR yang aman dan ramah lingkungan seperti APAR yang berisi gas cair; pengisian ulang APAR yang telah kedaluwarsa yang berada di gedung bedah Cempaka, Dahlia, dan Flamboyan; pemasangan APAR dengan ketinggian 1,2 $\mathrm{m}$ dari lantai sampai bagian atas APAR di semua gedung bedah RSUD Dr. Soetomo Surabaya

\section{DAFTAR PUSTAKA}

Angela, T.A. 2006. Studi Kasus Evaluasi Sistem Penanggulangan Kebakaran PT. Indogravure. Jurnal Kesehatan Masyarakat Nasional, 1: 63-68.

Arazzy, S., Elvi. S., Anita. R. 2014. Penerapan Sistem Manajemen Keselamatan Kebakaran di Rumah Sakit Dr. Sobirin Kabupaten Musi Rawas Tahun 2013. Jurnal Kesehatan Masyarakat Universitas Siwijaya: 103-111. 
Badan Standar Nasional. 2000. SNI 03-3989-2000 tentang Tata Cara Perencanaan dan Pemasangan Sistem Springkler Otomatik untuk Pencegahan Bahaya Kebakaran pada Bangunan Gedung. Jakarta.

Departemen Pekerjaan Umum. 2008. Peraturan Menteri Pekerjaan Umum No. 26/PRT/M/2008 tentang Persyaratan Teknis Sistem Proteksi Kebakaran pada Bangunan Gedung dan Lingkungan. Jakarta.

Departemen Perindustrian dan Perdagangan Republik Indonesia. 1998. Keputusan Menteri Perindustrian dan Perdagangan Republik Indonesia Tentang Larangan Memproduksi dan Memperdagangkan Bahan Perusak Lapisan Ozon serta Memproduksi dan Memperdagangkan Barang Baru yang Menggunakan Bahan Perusak Lapisan Ozon (Ozon Deplenting Substances). Jakarta.

Departemen Tenaga Kerja. 1980. Peraturan Menteri Tenaga Kerja dan Transmigrasi No. Per 04/ Men/1980 tentang Syarat-syarat Pemasangan dan Pemeliharaan Alat Pemadam Api Ringan. Jakarta.

Hambyah, F.R. 2016. Evaluasi Pemasangan APAR dalam Sistem Tanggap Darurat Kebakaran (Studi di Gedung Bedah RSUD Dr. Soetomo Surabaya). Skripsi. Surabaya, Universitas Airlangga.
Hesna, Y., Hidayat, B., Suwanda, S. 2009. Evaluasi Sistem Keselamatan Kebakaran pada Bangunan Gedung Rumah Sakit dr. M. Djamil Padang. Jurnal Rekayasa Sipi, Volume. 5, No. 2.

Luthfan F., Ekawati., Bina. K. 2014. Analisis Penerapan Alat Pemadam Api Ringan (APAR) Di PT. X Pekalongan. Jurnal Kesehatan Masyarakat e-Journal: 300-3008.

National Fire Protection Association. 2002. NFPA 10 Standard for Portable Fire Extinguishers 2002 Edition. One Batterymarch Park, Quincy, Massachusetts.

Ramli, S. 2010. Petunjuk Praktis Manajemen Kebakaran (Fire Management). Jakarta: Dian Rakyat.

Sanjaya, M., Maria, U. 2015. Evaluasi Sarana dan Prasarana Rumah Sakit dalam Menghadapi Bencana Kebakaran (Studi Kasus di RS PKU Muhammadiyah Yogyakarta Unit II). Jurnal Medicoeticoilegal dan Manajemen Rumah Sakit, Volume 4, No.2.

Supriyanto, Suhariono. 2015. Pedoman Teknis Manajemen Keselamatan dan Kesehatan Kerja Rumah Sakit. Surabaya: RSUD Dr. Soetomo.

Undang-undang Republik Indonesia Nomor 44 Tahun 2009 tentang Rumah Sakit. 